\title{
LIVER MICROSOMAL CYTOCHROME P-450-DEPENDENT O-DEALKYLATION REACTION IN VARIOUS ANIMALS
}

\author{
Takashi MATSUBARA, Shigemi OTSUBO and Emiko YOSHIHARA \\ Shionogi Research Laboratories, Shionogi \& Co. Ltd., \\ Fukushima-ku, Osaka 553. Japan
}

Accepted May 20, 1983

\begin{abstract}
Liver microsomal O-dealkylation activity was determined using O-methyl. $\mathrm{O}$-ethyl and $\mathrm{O}$-propyl derivatives of $\mathrm{p}$-nitrophenol, 7 -hydroxycoumarin (umbelliferon) and 7-hydroxyphenoxazone (resorufin) as substrates. Microsomal O-dealkylation activities of $p$-nitrophenol and 7-hydroxycoumarin 0 -alkyl derivatives were of similar levels, but the activities of 7-hydroxyphenoxazone 0 -alkyl derivatives were very low compared with those of other substrates. Pretreatment of rats with $\beta$-naphthoflavone resulted in the preferential increase of $\mathrm{O}$-deethylation and $\mathrm{O}$-depropylation activities regardless of the ring structure of the substrates, and the ratio of $\mathrm{O}$-deethylation and $\mathrm{O}$-depropylation activities to that of $\mathrm{O}$-demethylation increased markedly. On the other hand, the $\mathrm{O}$-dealkylase activity of all substrates increased generally upon pretreatment of the rats with phenobarbital, but the ratio of 0 -deethylase or $\mathrm{O}$-depropylase activity to that of $\mathrm{O}$-demethylase in the pretreated rats was not very different from that of the untreated animals. Hexobarbital inhibited competitively the O-dealkylation activity in control and phenobarbital-pretreated rat microsomes. On the other hand, the $\mathrm{O}$-dealkylase activity in microsomes obtained from $\beta$-naphthoflavone-pretreated rats was inhibited remarkably by $\alpha$-naphthoflavone, but not in microsomes prepared from untreated and phenobarbitalpretreated rats. Based on these results, this report discusses the relationship between the alteration of $\mathrm{O}$-dealkylation activity and the composition change of cytochrome P-450 in microsomal membrane. Species differences in the substrate specificity of the $\mathrm{O}$ dealkylation reaction and in the responsiveness of the animals to typical inducers were also observed using liver microsomes obtained from several animals under various conditions.
\end{abstract}

The hepatic microsomal cytochrome P-450 monooxygenase system functions in oxidative biotransformation of a wide variety of both endogenous and exogenous compounds $(1-$ 3). Recent studies have established the existence of multiple forms of cytochrome P-450 in liver microsomes obtained from various species of animals (4-6). and attempts to establish the substrate specificity of each form of cytochrome P-450 have hitherto been carried out using purified cytochrome P-450 or liver microsomes prepared from animals in various states $(5-8)$. The results indicate overlapping substrate specificities among various forms of the hemoprotein.

The O-dealkvlation reaction of various compounds was widely employed as a measure of cytochrome P-450-dependent monooxygenase (9-15). Recent studies have indicated a marked increase of the 0 dealkylase activity of 7-ethoxy- and 7aropoxy-coumarins, but not of 7-methoxycoumarin, in liver microsomes obtained from 3-methylcholanthrene- or $\beta$-naphthoflavonepretreated rats or some forms of purified cytochrome P-450. On the other hand. pretreatment of rats with phenobarbital 
resulted in a marked increase in the specific activity of the 0 -dealkylation reaction for all $\mathrm{O}$-alkyl derivatives of 7 -hydroxycoumarin (umbelliferon) (11, 16-18). The results indicate a close correlation between the cytochrome P-450 species and the substrate specificity of the $O$-dealkylation reaction for O-alkyl derivatives of 7-hydroxycoumarin. Thus, study of the O-dealkylation reaction for various compounds should be of interest to obtain further information.

This paper describes the O-dealkylation reaction of various substrates by liver microsomes obtained from animals in various states. Alteration of the substrate specificity in microsomal O-dealkylation reaction for various substrates were generally observed by pretreating animals with the typical inducers, phenobarbital and $\beta$-naphthoflavone. Inhibition of the 0 -dealkylation activity by $\alpha$ naphthoflavone or hexobarbital supports the close correlation between substrate specificity of the 0 -dealkylation reaction and molecular forms of cytochrome P-450. Species and strain differences in the $\mathrm{O}$-dealkylation reaction were also detected using liver microsomes obtained from untreated and microsomes obtained from untreated and phenobarbital- or $\beta$-naphthoflavone-pretreated animals.

\section{Materials and Methods}

Animals and their treatments: Adult male rats of the Wistar strain, 9 to 11 weeks old. were used. The rats were kept in an airconditioned room $\quad\left(25 \pm 1^{\circ} \mathrm{C}, \quad 50-60 \%\right.$ humidity) lighted 12 hr a day (8:00-20:00) and maintained on commercial rat chow (CA. 1. Japan Clea. Tokyo) and water ad libitum. Also used were the following adult male animals: mice (ICR and C57BL/6J strains, 10-11 weeks old), rabbits (JW-NIBS/ Rabiton, $2.5-3.0 \mathrm{~kg}$ ) and guinea pigs (Hartly, 300-350 g). They were kept under similar conditions. Some of the animals were intra- peritoneally given phenobarbital in physiological saline or $\beta$-naphthoflavone in sesame oil once a day for 3 consecutive days at the dose of $40 \mathrm{mg} / \mathrm{kg}$ body weight. Non-fasted animals were decapitated one day after the last injection, and the livers were quickly removed. Rabbits were killed under ether anaethesia. Liver microsomes were prepared as described previously (17).

Analytical and assay methods: Microsomal protein concentration was determined by the method of Lowry et al. (19) using bovine serum albumin as standard. Cytochrome P. 450 was determined according to the method of Omura and Sato (20) using a Shimadzu UV-300 spectrophotometer

Microsomai $\mathrm{O}$-dealkylation activity was determined by measuring the $\mathrm{O}$-dealkylated metabolite produced in the reaction mixture during the incubation. A typical incubation mixture for the assay contained liver microsomes, NADPH-generating system 10.25 imoles NADP. 2.5 imoles glucose 6 phosphate and $0.651 . \cup$. glucose 6 -phosphate dehydrogenase) and a substrate in $1.5 \mathrm{ml}$ of a buffer mixture (50 mM Tris- $\mathrm{HCl}$ buffer, $\mathrm{pH}$ 7.4. containing $150 \mathrm{mM} \mathrm{KCl}$ and $10 \mathrm{mM}$ $\left.\mathrm{MgCl}_{2}\right)$. The amounts of substrates added to the $1.5 \mathrm{ml}$ of incubation mixture were $0.60-$ 0.65 umole. 0.46-0.57 umole and 0.10 0.11 zmole for the $\mathrm{O}$-alkyl derivatives of p-nitrophenol, 7 -hydroxycoumarin and resorufin (7-hydroxyphenoxazone), respectively: these were concentrations that were similar to levels used in previous reports $(12$. 17. 18, 21). Lower concentrations of 7 hydroxyphenoxazone $\mathrm{O}$-alkyl derivatives were due to their low solubility. The reaction was ir tiated by adding microsomes and carried out at $37^{\circ} \mathrm{C}$ with moderate shaking. The $\mathrm{O}$ dealkylation activity of $p$-nitroanisole and $p$ nitrophenetole was determined essentially as described by Shigematsu et at. (21). Microsomal 7-alkoxycoumarin O-dealkylase activity was determined by the fluorometric 
measurement of 7-hydroxycoumarin produced in the incubation mixture (18).

$\mathrm{O}$-dealkylation activity of alkoxyresorufin was determined by the fluorometric detection of resorufin. After aerobic incubation of the reaction mixture for $3-5 \mathrm{~min}$, the reaction was terminated by adding $1.0 \mathrm{ml}$ of $0.25 \mathrm{M}$ perchloric acid (PCA) $-0.75 \mathrm{M}$ glycine mixture followed by $0.5 \mathrm{ml}$ of $5.4 \%(\mathrm{~W} / \mathrm{v}) \mathrm{K}_{2} \mathrm{CO}_{3}$, and then the protein precipitate was spun down. A portion $(0.1-0.2 \mathrm{ml})$ of the resulting supernatant was mixed into $2.5 \mathrm{ml}$ of $0.1 \mathrm{M}$ carbonate-bicarbonate buffer $(\mathrm{pH} 10)$, and then the fluorescence intensity was moasured at $583 \mathrm{~nm}$ with an excitation of $550 \mathrm{~nm}$. The blank consisted of the complete reaction mixture to which the substrate was added after addition of the PCA-glycine mixture.

The fluorescence of resorufin, but not of alkoxyresorufin, was intensified in alkaline solution: and the excitation and emission wavelengths of resorufin obtained at $\mathrm{pH} 10$ were 570 and $583 \mathrm{~nm}$, respectively. Meanwhile, alkoxyresorufin showed excitation and emission wavelengths at 470 and $570 \mathrm{~nm}$, respectively, and its fluorescence property was not altered by the $\mathrm{pH}$ change. Based on these fluorescence properties of resorufin and its 0 -alkyl derivatives, the fluorometric determination of resorufin produced in the reaction mixture during the incubation was performed at $583 \mathrm{~nm}$ with excitation at $550 \mathrm{~nm}$ to minimize the effect of excitation light-scattering. Under the fluorometric assay conditions employed, the relative fluorescence intensities of alkoxyresorufin and resorufin were 0.16 and 100 . respectively. Resorufin and its 0 -alkyl derivatives in the complete reaction mixture were stable even after the addition of the PCA-glycine mixture, and the fluorescence spectra were not affected by this treatment. The recovery of resorufin was determined by adding various amounts of resorufin $(0.60-$ $10.0 / \mathrm{M}$ ) to the microsomal suspension, and the recovery ranged from 85-92\%.

Synthesis of alkoxyresorufin (7-alkoxyphenoxazone): The O-methyl. O-ethyl and O-propyl derivatives of resorufin were synthesized using the corresponding alkyl iodides essentialiy as for the synthesis of 7-alkoxycoumarin (17). Resorufin (2 g), alkyl iodide $(25 \mathrm{~g})$ and potassium hydroxide $(1.0-1.2 \mathrm{~g})$ in $270 \mathrm{ml}$ methanol were incubated at 60$70^{\circ} \mathrm{C}$ for $6-12 \mathrm{hr}$. After evaporation of the methanol under reduced pressure, the products were dissolved in a dichloromethane$\mathrm{H}_{2} \mathrm{O}$ mixture $(10: 2-3, v / v)$, and the dichloromethane phase was washed several times with $1 \%(w / v) \mathrm{KOH}$ until the aqueous phase was clear. Next, the solvent was evaporated. and the products were dissolved in a dichloromethane-acetone mixture $(10: 1, \mathrm{v} / \mathrm{v})$. The product (alkoxyresorufin) was then separated by silica gel column chromatography using the dichloromethane-acetone mixture $(10: 1, v / v)$ as the solvent system. and crystallized in a dichloromethane-ethanol system. The melting points of crystalline methoxy-, ethoxy- and propoxy-resorufins were $255-257,218-220$ and $183-185^{\circ} \mathrm{C}$. respectively. Analytical data of the alkoxyresorufin thus synthesized are as follows: 1) Methoxyresorufin. Calculated for $\mathrm{C}_{13} \mathrm{H}_{9} \mathrm{NO}_{3}$ : C. $68.72 \% ; H .3 .99 \% ; N .6 .16 \%$. Found: C. $68.40 \% ; H, 4.22 \% ; N, 6.14 \% .2)$ Ethoxyresorufin. Calculated for $\mathrm{C}_{14} \mathrm{H}_{11} \mathrm{NO}_{3}$ : C. $69.70 \% ; H .4 .60 \%$; N. 5.81\%. Found: C. $69.02 \% ; H, 4.51 \% ; N, 5.84 \% .3)$ Propoxyresorufin. Calculated for $\mathrm{C}_{15} \mathrm{H}_{13} \mathrm{NO}_{3}$ : C. 70.58\%; H. 5.13\%: N. 5.49\%. Found: C. $70.47 \% ; H, 5.16 \% ; N, 5.41 \%$.

Chemicals: NADP, glucose 6-phosphate and glucose 6-phosphate dehydrogenase were purchased from Oriental Yeast Co. (Tokyo); resorufin, from Kanto Kagaku Co. (Tokyo): 7-hydroxycoumarin, from Nakarai Chemicals (Osaka) and hexobarbital, from Shionogi \& Co. (Osaka). 7-Hydroxycoumarin O-methyl-, O-ethyl- and O-propyl- 
derivatives were synthesized as described previously (17). Other chemicals of the purest grade available were obtained commercially and used for the experiments without further purification.

\section{Results}

Alteration of hepatic O-dealkylation activity following administration of phenobarbital and $\beta$-naphthoflavone: Microsomal $\mathrm{O}$-demethylation and $\mathrm{O}$-deethylation reactions have been studied widely using $p$ nitroanisole (14), p-nitrophenetole (21, 22), 7 -ethoxycoumarin $(9,23-25)$ and 7ethoxyresorufin $(12,13)$ as substrates. Recent studies indicated that the aiteration of substrate specificity in microsomal 7 alkoxycoumarin $\mathrm{O}$-dealkylase is closely correlated to the composition change of cytochrome P.450's in microsomal membrane $(11,16-18)$. It is thus interesting to compare microsomal $\mathrm{O}$-dealkylation activity using $\mathrm{O}$ alkyl derivatives of various chemicals as model substrates (Fig. 1). When 7-alkoxycoumarin was employed as the substrate. pretreatment of rats with phenobarbital resulted in increase of the $\mathrm{O}$-dealkylation activity for all 0 -alkyl derivatives of 7 hydroxycoumarin tested. On the other hand, the O-deethylation and O-depropylation activities, but not the $\mathrm{O}$-demethylation

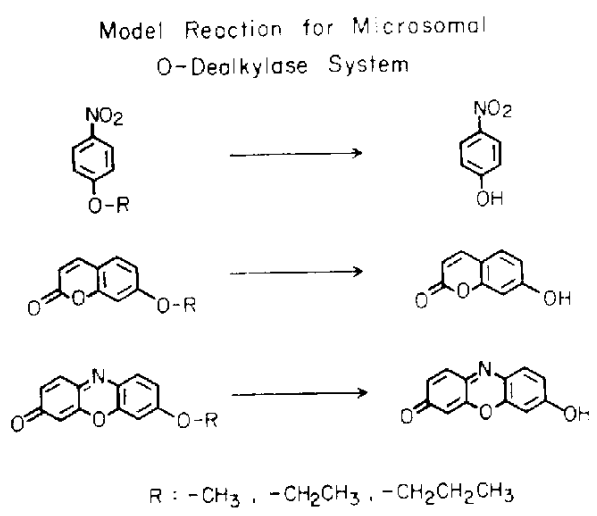

Fig. 1. Model reaction for microsomal O-dealkylase. activity, of 7-alkoxycoumarin increased remarkably in liver microsomes obtained from $\beta$-naphthofiavone-pretreated rats (Table 1). Cytochrome P-450 (P-448) content in liver microsomes increased markedly upon pretreatment of the rats with either phenobarbital or $\beta$-naphthoflavone (Table 3 ).

When $p$-nitrophenol 0 -alkyl derivatives, $p$ nitroanisole and $p$-nitrophenetole, were employed as substrates, both O-demethylation and $\mathrm{O}$-deethylation activities increased markedly with pretreatment of the rats with phenobarbital. Pretreatment of rats with $\beta$ naphthoflavone resulted in a marked increase of the $\mathrm{O}$-deethylation activity of p-nitrophenetole, while the $\mathrm{O}$-demethylation activity of p-nitroanisole increased only slightly compared to the $\mathrm{O}$-deethylation activity (Table 1).

Microsomal 0 -dealkylation activity of 7 hydroxyphenoxazone $\mathrm{O}$-alkyl derivatives in control rats was very low compared to that of $p$-nitrophenol and 7 -hydroxycoumarin $\mathrm{O}$ alkyl derivatives. Pretreatment of rats with phenobarbital resulted in increase of the microsomal 0 -depropylation activity of 7 propoxyresorufin, but only a slight or no effect on the O-deethylation or O-demethylation activity, respectively. Administration of $\beta$-naphthoflavone caused an increase in the $\mathrm{O}$-deakylation activity of 7 -alkoxyresorufin, and the increase in the $\mathrm{O}$-deethylation and $\mathrm{O}$ depropylation activities was much more prominent than the $\mathrm{O}$-demethylation activity (Table 1). The results shown in Table 1 indicate that microsomal O-dealkylation activity of various substrates increased generally with pretreatment of rats with phenobarbital, but the ratio of $\mathrm{O}$-deethylase or $\mathrm{O}$-depropylase activity to that of $\mathrm{O}$ demethylase in the pretreated animals was not very different from those of the control or untreated animals. On the other hand. pretreatment of rats with $\beta$-naphthoflavone or 3-methylcholanthrene (17) resulted in the 
Table 1. Effect of phenobarbital-or $\beta$-naphthoflavone-administration on liver microsomal 0 -dealkylation activity in rats

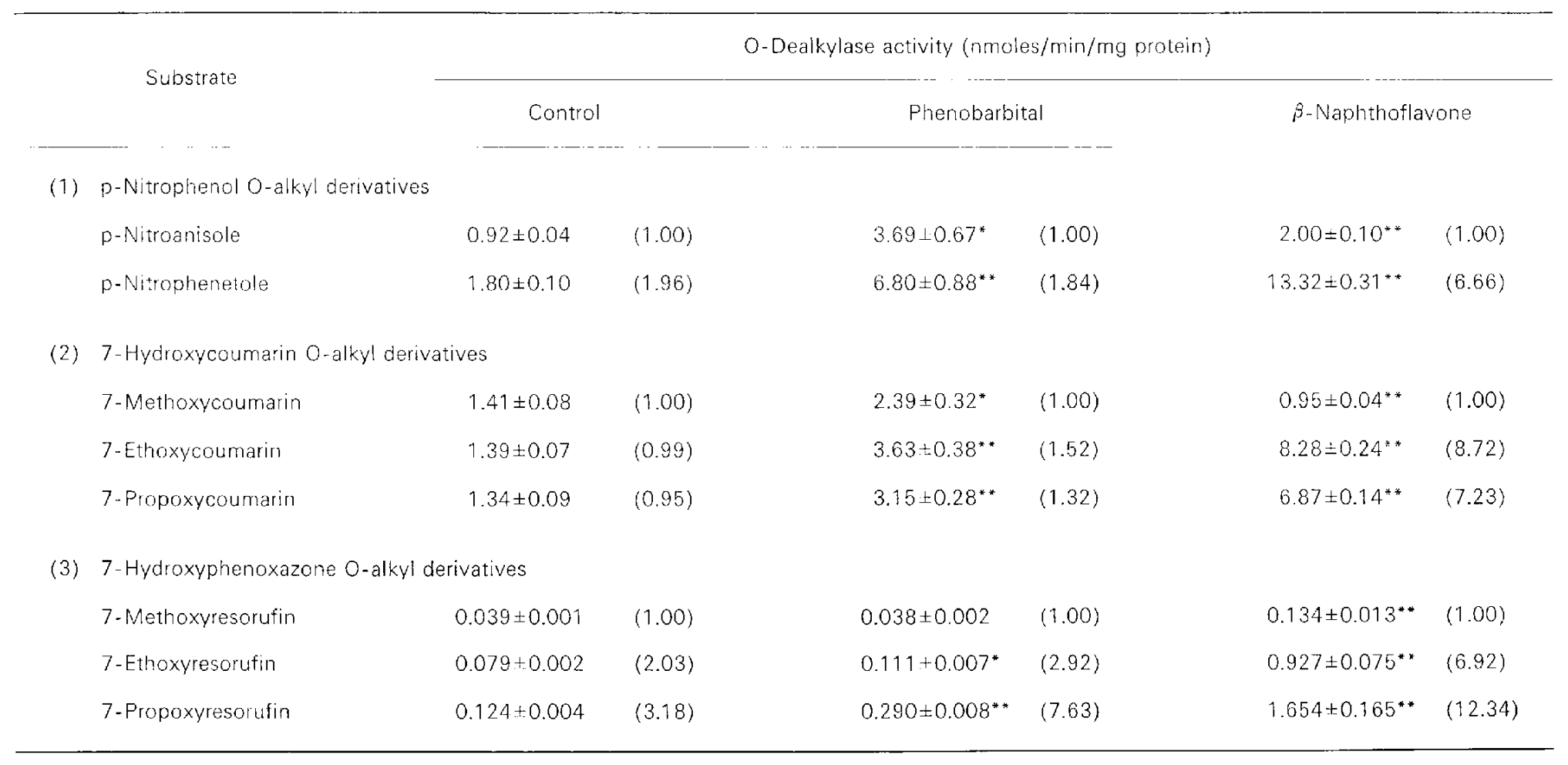

The values represent the mean \pm S.E. of 3 animals, and the number in the bracket is the ratio of the activity to the corrosponding 0 -demethylase activity. *Statistically significant $(\mathrm{P}<0.05)$ against the control group. * Statistically significant $(\mathrm{P}<0.01)$ against the control group. 
preferential increase of $\mathrm{O}$-deethylation and $\mathrm{O}$ depropylation activities, and the ratio of $\mathrm{O}$ deethylation and $\mathrm{O}$-depropylation activities to that of $O$-demethylation increased remarkably regardless of the fundamental ring structure of the chemicals employed. The results indicate a close relationship between the substrate specificity of the 0 -dealkylation reaction and the molecular form of the cytochrome P-450's.

Effect of hexobarbital and $\boldsymbol{\alpha}$-naphthoflavone on microsomal $\mathrm{O}$-dealkylase system: The in vitro effects of hexobarbital and $\alpha$ naphthoflavone were studied to clarify the correlation between substrate specificity of the 0 -dealkylation reaction and the molecular form of cytochrome P-450, employing the 7-alkoxycoumarin $\mathrm{O}$-dealkylation reaction as a model. Addition of typical type I compound. hexobarbital (26), to the incubation mixture for the O-dealkylase assay resulted in intiibition of tho microsomal O-dealkylation activity in untreated (intact) and phenobarbital-pretreated rats, while the activity in

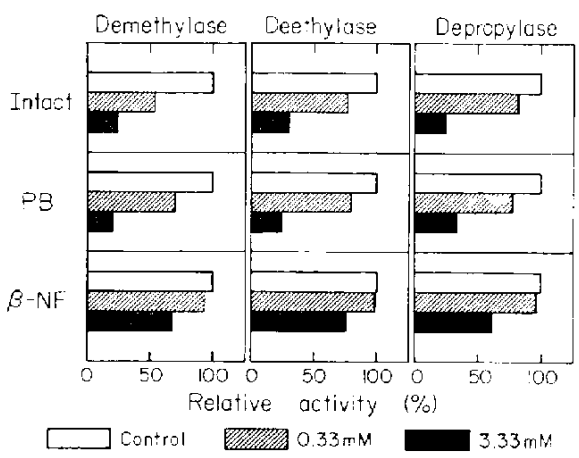

Fig. 2. Effect of hexobarbital on microsomal 7 alkoxycoumarin 0 -dealkylase. 7 -Akoxycoumarin 0 doakylation activity has determined using liver microsomos obtainod from intact (un:leated) and phenobarial (PB)- or is-naphthoflavone (j NF)pretreated rats. The 0 -dealkylation activity detected in the presence of 0.33 and $3.33 \mathrm{~mm}$ hexobarbital is expressed as the percentage of the value in the absence of hexobarbital. Microsomal concentrations in the reaction mixture were $0.74,0.74$ and $0.85 \mathrm{mg}$ protein $/ \mathrm{ml}$ in intact, PB-pretreated and P.NF pretreated rats, respectively.
B-naphthoflavone-pretreated rats was affected only slightly by higher concentrations (3.33 $\mathrm{mM}$ or more) of hexobarbital (Fig. 2). The inhibitory pattern of hexobarbital was further examined by adding various concentrations of the compound to the incubation mixture. As shown in Fig. 3, higher 0 dealkylation activity was obtained by adding more substrate, and the activity was depressed gradually by the addition of increased concentrations of hexobarbital. The Dixon plot (Fig. 3. inset) clearly shows that the $\mathrm{O}$ dealkylation activity was inhibited competitively by hexobarbital. The inhibitory pattern of hexobarbital was the same regardless of the microsomal species and 0 -alkyl group substitution of the substrate. The inhibition constants $\left(K_{i}\right)$ of hexobarbital thus obtained are summarized in Table 2. The constant calculated for untreated rat livor microsomes increased following elongation of the alkylchain length of the substrate. and no differ ence in the values was observed when liver microsomes prepared from untreated and phenobarbital-pretreated rats were used. On the other hand, the inhibition constants

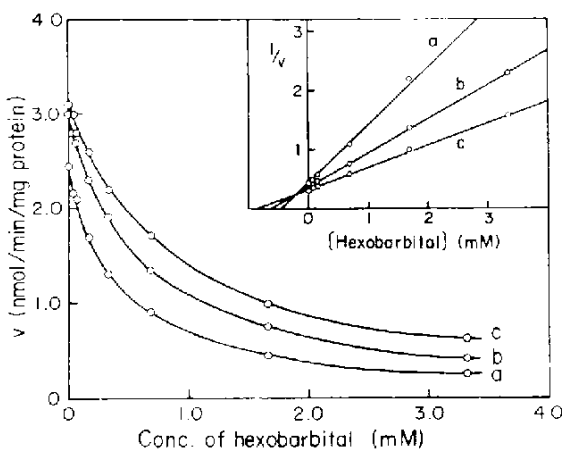

Fig. 3. Inhibition ol microsomal 7-alkoxycoumarin 0 -dealkylase by hoxobarbital. The activity in various concentrations of hexobarbital was determined by adding (a) 114 , (b) 227 or (c) $379, \mu M 7$-metloxycoumarin as substrato. Liver microsomos obtained from prenobarbital-pretreated rats were added to the incubation mixture at the concentration of 0.74 $\mathrm{mg}$ protein $/ \mathrm{ml}$. The inset is a Dixon plot showing the effect of rexobarbital on 7-methoxycoumarin O-demethylase 
Table 2. 'Thibition constants of hexobarbital and a-naphthoflavone for microsomal 7-alkoxycoumarin O-dealkylase

\begin{tabular}{|c|c|c|c|}
\hline & $\begin{array}{c}\text { O. Demethylation } \\
\text { reaction }\end{array}$ & $\begin{array}{c}\text { tion constant }(\mu \mathrm{N} \\
\text { - Deethylation } \\
\text { reaction }\end{array}$ & $\begin{array}{l}\text { O-Depropylation } \\
\text { reaction }\end{array}$ \\
\hline \multicolumn{4}{|l|}{ Inhibition by hexobarbita: } \\
\hline Control rat & 35 & 280 & 550 \\
\hline PB-pretreated rat & 125 & 300 & 500 \\
\hline$\hat{j}-\mathbb{N} F$-pretreated rat & 650 & 1,700 & 1.170 \\
\hline \multicolumn{4}{|c|}{ Inhibition by $\alpha$-naphthoflavone } \\
\hline S-NF-pretreated rat & 1.8 & 1.1 & 0.4 \\
\hline
\end{tabular}

Abbreviations: PB, prenobarbital: $\beta$-NF. $\beta$-naphithoflavone.

obtained for $\beta$-naphthoflavone-pretreated rat microsomes were quite different from the others and very high values were observed (Table 2).

The effect of $\alpha$-naphthoflavone, a specific inhibitor of microsomal cytochrome P-448 dovendent hydroxylation reactions (27), upon microsomal 7-alkoxycoumarin O-doalkylase was also determined. As shown in Fig. 4. the $O$-dealkylation activity in liver microsomes obtained from $\beta$-naphthoflavone-pretreated rats was inhibited remarkably by $\alpha$-naphthoflavone, and the inhibitory pattern was a competitive one (data not shown). On the contrary, the $\mathrm{O}$-doalkylase activity in untreated and phenobarbital-pretreated rats was not inhibited by $\alpha$-naphthoflavone. The inhibition constants of $\alpha$-naphthoflavone for inhibition of the 0 -dealkylation reaction in $\beta$ naphthoflavone-pretreated rat liver microsomes are shown in Table 2. which shows that the lowest inhibition constant appeared in the $\mathrm{O}$-depropylation reaction.

Comparison of 7-alkoxycoumarin $\mathrm{O}$ dealkylation activity among various species of animals: Marked species diffcrences in the metabolism of drugs have become evident during the past two decades (28). Thus, the 0 -dealkylation activity has been studied using liver microsomes obtained from various species of animals. As observed in rat liver microsomes (Table 1), changing the alkyl

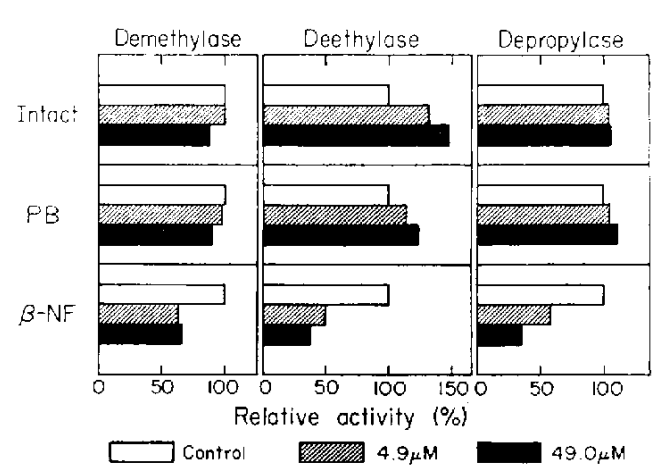

Fig. 4. Effect of $\alpha$-naphthoilavono on microsomal 7-alkoxycoumarin O-dealkylase. Microsomal Odealkylase activity was determined as described in the legend of rig. 2, using $\alpha$-naphthoflavone as the inhibitor instead of hexobarbital. Concentrations of \&-raphtroflavone added were 4.9 and $49.0 \mu \mathrm{M}$. Microsomal concentrations in intact (untreated). phenobarbital (PB)-pretreated and $\beta$-naphthoflavone ( $\beta-N F)$-pretreated rats were $1.36,1.03$ and $1.33 \mathrm{mg}$ protein $/ \mathrm{ml}$ of incubatior mixture. respectively.

group of the substrate from a methyl to a propyl group resulted in marked alteration in the $\mathrm{O}$-dealkylation activities in all microsomes tested. When microsomes obtained from untreated animals were employed, the $\mathrm{O}$ demethylation activity was generally the highest and $\mathrm{O}$-depropylation activity the lowest (Table 3), although little or no difforence was found between them in rat liver microsomes. Administration of phenobarbital caused increases in cytochrome P- 
Table 3. Effect of pretreatment of animals with phenobarbital and $\beta$-naphthoflavone on liver microsomal 7 -alkoxycoumarin 0 -dealkylase in various adult male animals

\begin{tabular}{|c|c|c|c|c|c|c|}
\hline \multirow{2}{*}{ Animal } & \multirow{2}{*}{$\begin{array}{l}\text { Pretreatment } \\
\text { of anima! }\end{array}$} & \multirow{2}{*}{$\begin{array}{l}\text { No. of } \\
\text { animals }\end{array}$} & \multicolumn{3}{|c|}{ 7-Alkoxycoumarin O-deaikylase (nmol/min/mg protein) } & \multirow{2}{*}{$\begin{array}{l}\text { Cytochrome P-450 } \\
\text { (nmol/mg protein) }\end{array}$} \\
\hline & & & $\begin{array}{l}\text { 7- Methoxyoumarin } \\
\text { O-demothylaso }\end{array}$ & $\begin{array}{l}\text { 7-Ethoxycoumarin } \\
\text { O-decthylase }\end{array}$ & $\begin{array}{l}\text { 7-Propoxycoumarin } \\
\text { O-depropylase }\end{array}$ & \\
\hline \multirow{4}{*}{ Rat } & & - & & - & & $\cdots-$ \\
\hline & Nono (control) & 3 & $1.34 \pm 0.10$ & $1.61 \pm 0.17$ & $1.61 \pm 0.20$ & $1.12 \pm 0.03$ \\
\hline & $\mathrm{PB}$ & 3 & $2.32+0.10^{* *}$ & $4.15 \pm 0.32^{* *}$ & $3.68 \pm 0.23^{* *}$ & $1.93=0.16^{* *}$ \\
\hline & $\hat{\beta}-N F$ & 3 & $1.04 \pm 0.08$ & $7.95 \pm 0.45^{* *}$ & $8.03+0.46^{* *}$ & $2.19+0.06^{* *}$ \\
\hline Mouse & None (control) & $10(3)$ & $2.18 \pm 0.05$ & $1.70 \pm 0.30$ & $0.74 \pm 0.17$ & $2.33 \pm 0.15$ \\
\hline \multirow[t]{2}{*}{$(I C R)$} & PB & $11(3)$ & $2.87+0.17$ & $2.48 \pm 0.20$ & $0.87+0.07$ & $3.65 \pm 0.44^{*}$ \\
\hline & $\beta-N F$ & $11(3)$ & $2.34 \pm 0.29$ & $2.06 \pm 0.22$ & $0.77 \pm 0.09$ & $2.27 \pm 0.30$ \\
\hline Mouse & None (control) & $12(3)$ & $2.29 \pm 0.10$ & $2.47 \pm 0.12$ & $1.02 \pm 0.09$ & $0.99+0.01$ \\
\hline \multirow[t]{2}{*}{$(C 57 \mathrm{BL} / 6 . J)$} & $\mathrm{PE}$ & $12(3)$ & $4.99 \pm 0.03^{* *}$ & $5.62 \pm 0.13^{x x}$ & $1.91 \pm 0.07^{* *}$ & $1.67 \pm 0.05^{* *}$ \\
\hline & $\beta-N t$ & $12(3)$ & $3.03 \pm 0.12^{*+}$ & $4.81 \pm 0.32^{* *}$ & $2.27+0.20^{* *}$ & $1.78 \pm 0.11^{* *}$ \\
\hline \multirow[t]{3}{*}{ Rabbit } & None (control) & 4 & $1.06 \pm 0.01$ & $1.06+0.11$ & $0.54+0.04$ & $1.23 \pm 0.19$ \\
\hline & PB & 4 & $4.74 \pm 0.56^{* *}$ & $4.77 \pm 0.59^{x x}$ & $1.99 \pm 0.34^{* *}$ & $3.10 \pm 0.18^{* *}$ \\
\hline & $\beta-N F$ & 4 & $1.24 \pm 0.16$ & $1.33 \pm 0.15$ & $0.64 \perp 0.10$ & $3.97 \cdot 10.25^{* *}$ \\
\hline \multirow[t]{3}{*}{ Guinea pig } & None (control) & 4 & $2.44 \pm 0.32$ & $1.69 \pm 0.22$ & $0.84 \pm 0.18$ & $1.83 \pm 0.12$ \\
\hline & $\mathrm{PB}$ & 4 & $5.32+0.07^{* *}$ & $4.37 \pm 0.05^{* *}$ & $0.96 \pm 0.07$ & $3.04 \pm 0.11^{*}$ \\
\hline & $\beta-N F$ & 4 & $3.07 \pm 0.38$ & $1.54 \pm 0.17$ & $0.48 \pm 0.07$ & $2.32 \pm 0.18$ \\
\hline
\end{tabular}

The animals wore administered intraperitoncally phenobarbital (PB) or $\beta$-naphthoflavone ( $\beta$-NF) at the dose of 40 mog/kg for 3 days. Mouse liver microsomes were prepared using pooled livers from 3-4 animals, and the number of microsomal preparations is in parenthesis. The values in the Table represont the Mean $\pm S$.E. *Statistically significant $(P<0.05)$ against the contro! group. "Statistically significant $(P<0.01)$ against the control group. 
450 content and the 0 -dealkylation activity for all 7-alkoxycoumarins in all animals tested. When liver microsomes obtained from $\beta$-naphthoflavone-pretreated mice (C57BL/6J strain) were employed, marked increases were found in cytochrome P-450 (P-448) content and in O-dealkylation activity of 7-ethoxy- and 7-propoxycoumarins, as in rats. Interestingly, pretreatment of rabbits with $\beta$-naphthoflavone resulted in a marked increase in cytochrome P-450 (P-448) content, but the O-dealkylase activity was not affected. Under the experimental conditions employed, the $\mathrm{O}$-dealkylase activity and the cytochrome content in guinea pigs and the ICR strain of mice were not altered by the administration of $\beta$ naphthoflavone (Table 3). The results shown in Table 3 suggest marked species and strain differences in the composition of cytochrome $\mathrm{P}-450$ isozyme in microsomal membrane and in the inducibility of the cytochrome P-450 (P-448) monooxygenase system by $\beta$ naphthoflavone.

\section{Discussion}

Recent studies have indicated that alteration of specific activity or substrate specificity in the $\mathrm{O}$-dealkylation reaction of 7-alkoxycoumarin reflects the alteration of molecular forms of cytochrome P-450's in liver microsomes (16-18). Pretreatment of rats with phenobarbital or $\beta$-naphthoflavone also resulted in alterations of substrate specificity in the $\mathrm{O}$-dealkylation reaction of O-alkyl derivatives of $p$-nitrophenol and 7 hydroxyphenoxazone (Table 1). suggesting the participation of a specific form of cytochrome P-450 in the reaction. Several investigators have reported microsomal 0 deethylation reactions of 7 -ethoxycoumarin. 7-ethoxyresorufin and p-nitrophenetole, which are preferentially inducible by 3 methylcholanthrene or $\beta$-naphthoflavone. more than phenobarbital $(9,12,13,22,23$.
25, 29). When O-alkyl derivatives of these chemicals were used as substrates, liver microsomes obtained from $\beta$-naphthoflavone-pretreated rats preferentially catalyze not only the $\mathrm{O}$-deethylation reaction, but also the O-depropylation reaction of all substrates tested (Table 1). The inhibitory effect of $\alpha$-naphthoflavone on the $\mathrm{O}$ dealkylation reaction in $\beta$-naphthoflavonepretreated rats suggests that the reaction is catalyzed by cytochrome P-448 (Fig. 4). When the $\mathrm{O}$-dealkylase activities in $\beta$ naphthoflavone-pretreated rats were determined in the presence of rabbit antibodies against the phenobarbital-induced form ( $P$ $\left.450_{\mathrm{PB}}\right)$ and the 3-methylcholanthreneinducible form $\left(\mathrm{P}-45 \mathrm{O}_{\mathrm{HO}}\right.$ ) of rat liver microsomal cytochrome $\mathrm{P}-450$, both $\mathrm{O}$-deethylation and $\mathrm{O}$-depropylation activities were depressed preferentially by the antibody against $P-450_{n o}$. but the antibody against $P-450_{\mathrm{PB}}$ did not affect the activities (unpublished results). These results also support that cytochrome P-448 preferentially catalyzes the $\mathrm{O}$-deethylation and $\mathrm{O}$-depropylation reactions of 7-alkoxycoumarin.

Administration of phenobarbital resulted in increase of microsomal O-dealkylation activity for all substrates, but no remarkable alteration in the substrate specificity like that observed in the cytochrome P-448-dependent reaction was obtained by phenobarbital treatment (Table 1). Competitive inhibition of the microsomal $\mathrm{O}$-dealkylation reaction by hexobarbital (Figs. 2 and 3 ) indicates that some forms of cytochrome P-450 interact specifically with hexobarbital and 7-alkoxycoumarin, and these chemicals compete for the same binding site on the hemoprotein(s). Interestingly, the inhibition constant for hexobarbital inhibition in phenobarbitalpretreated rats was almost the same as that in control rats (Table 2), suggesting also that the phenobarbital-inducible form(s) of cytochrome P-450 has similar substrate specificity 
to that of the constitutive form(s) of the cytochrome with respect to the O-dealkylation reaction of 7-alkoxycoumarin. Addition of antibody against $\mathrm{P}-45 \mathrm{O}_{\mathrm{PB}}$, but not $\mathrm{P}$ $450_{M c}$, to the incubation mixture for the $\mathrm{O}$ dealkylase assay caused the inhibition of the activity in phenobarbital-pretreated rats (unpublished results). The results also support the participation of phenobarbital-inducible form(s) of cytochrome P-450's in the increased 0 -dealkylation activity of the pretreated rats. Clarification of the relationship between every isozyme of purified cytochrome P-450 and substrate specificity in the $\mathrm{O}$-dealkylation reaction remains a subject for further study.

Species and strain differences in drug metabolism are well established, and qualitative or quantitative differences are observed depending upon the drugs employed. The differences were also detected in the case of the O-dealkylation reaction of 7-alkoxycoumarin (Table 3). Pretreatment of animals with phenobarbital caused increases in cytochrome P-450 content and in the $\mathrm{O}$ dealkylation activity in all animals tested. On the other hand, species differences in the inducibility of the microsomal $\mathrm{O}$-dealkylase system by $\beta$-naphthoflavone were obtained: a marked increase in the $\mathrm{O}$-dealkylase system upon pretreatment of the animals with $\beta$ naphthoflavone was observed only in rats and C57BL/6J strain mice. Interestingly, administration of $\beta$-naphthoflavone to rabbits caused a marked increase of cytochrome P-450 (P-448) content, but the O-dealkylation activity was not influenced (Table 3). The results agree with the report of Levine et al. (30) that little or no catalytic activity of benzo (a) pyrene hydroxylation occurs with 3 methylcholanthrene-induced rabbit liver cytochrome P-448. Inducibility of microsomal 0 -dealkylase in various species of animals by $\beta$-naphthoflavone (Table 3) may be correlated with the Ah locus characteristics (27.
31), and then the relationship should be clarified between species differences in the 0 -dealkylation reaction and molecular species of cytochrome P-450 in different animals.

\section{References}

1) Estabrook, R.W.: Cytochrome P-450. Its function in the oxidative metaoolism of drugs. in Handbuch der Experimentallen Pharmakologie. Edited by Brodie. B. B. and Gillette. J., Vol. 27, Part 2, p. 264-284. Springer Verlag, Berlir (1971)

2) Gillette, J.R., Davis, D.C. and Sasame, H.A.: Cytochrome P-450 and its role in drug metabolism. Annu. Rov. Pharmacol. 12, 57-84 (1972)

3) Trager, W.F.: Oxidative functionalization reactions. In Concepts in Drug Mctabolism. Edited by Jenner. P. and Testa, B., Part A, p. 177-209. Marcel Dekker. New York (1980)

4) Guengerich, F.P.: Isolation and purification of cytochrome P-450, and the existence of muliple forms. Pharmacol. Ther. 6, 99-121 (1979)

5) Haugen, D.A., van der Hoeven, T.A. and Coon, M.J.: Purified liver microsomal cytochrome P-450. Separation and characterization of muitiple forms. J. Biol. Chem. 250, 3567-3570 (1975)

6) Huang, M.-T., West, S.B. and Lu, A.Y.H.: Separation, purification, and proporties of multiple forms of cytochrome P-450 from the liver microsomes of phenobarbital-pretreated mico. J. Biol. Chom. 251, 4659-4665 (1976)

7) Ryan, D.E., Thomas, P.E., Korzenioski, D. and Levin, W.: Separation and characterization of highly purified forms of liver microsomal cytocinome P-450 from rats treated with polychlorinated biphenyls, phenobarbital and 3-methylcholanthrene. J. Biol. Chem. 254, 1365-1374 (1979)

8) Cheng, K.C. and Schenkman, J.B.: Purification and characterization of two constitutive forms of rat liver microsomal cytochrome P-450. J. Biol. Chem. 257, 2378-2385 (i982)

9) Ullrich, $V$. and Weber, P.: The O-dealkylation of 7-ethoxycoumarin by liver microsomes: $A$ direct fluorometric test. Hoppe Seylers Z. Physiol. Chom. 353, 514-520 (1973)

10) Kapitulnik, J., Popper, P.J. and Conney, A.H.: Comparative metabolism of benzo(a)pyrene and drugs in human liver. Clin. Prarmacol. Ther, 21, 160-176 (1977)

11) Imai, Y.: Reconstituted O-dealkylase system containing various forms of liver microsomal 
cytochrome P-450. J. Biochem. (Tokyo) 86, 1697-1707 (1979)

12) Burke, M.D. and Meyer, R.T.: Ethoxyresorufin: Direct fluorimetric assay of a microsomal $\mathrm{O}$ dealkylation which is preferentially inducible by 3 -methylcholanthrene. Drug Metab. Dispos. 2, 583-588 (1974)

13) Burke, M.D. and Meyer, R.T.: Inherent specificities of purified cytochromes P-450 and P-448 towards biphenyl rydroxylation and ethoxyrosorfin deethylation. Drug Metab. Dispos. 3, 245-253 (1975)

14) Netter, K.J. and Seidel, G.: An adaptively stimulated $\mathrm{O}$-deetiylating system in rat liver microsomes and its kinetic properties. J. Pharmacol. Exp. Ther. 146, 6?-65 (1964)

15) Alpert, A.J. and Cavalieri, E.L.: Metabolism of 6 -substituted benzo(a)pyrene derivatives: 0 dealkylation and regiospecificity in aromatic hydroxylation. J. Med. Chem. 23, 919-927 (1980)

16) Kamataki, T., Ando, M., Yamazoe, Y., Ishii, K. and Kato, R.: Sex differences in the $O$ dealkylation activity of 7-hydroxycoumarin 0 alkyl derivatives in liver microsomes of rats. Biochom. Pharmaco!. 29, 1015-1022 (1980)

17) Matsubara, T., Yoshihara, E., Iwata, T., Tochino, $Y$. and Hachino, $Y .:$ Biotransformation of coumarin derivatives. (1) 7-Alkoxycoumarin O-dealkylase in liver microsomes, japan. J. Pharmacol. 32, 9-21 (1982)

18) Matsubara, T., Otsubo, S., Yoshihara, E. and Touchi. A.: Biotransformation of coumarin derivatives. (2) Oxidative metabolism of 7 alkoxycoumarin by microsomal enzymes and a simple assay procedure for 7 -alkoxycoumarin O-doalkylase. Japan. J. Pharmacol. 33, 41-56 (1983)

19) Lowry, O.H., Rosenbrough, N.J., Farr, A.L. and Randall, R.J.: Protein measurement with the Folin phenol reagont. J. Biol. Chem. 193, 265-275 (1951)

20) Omura, T. and Sato, R.: The carbon monoxidebinding pigment of liver microsomes. I. Fvidence for its hemoprotein nature. J. Biol. Chem. 239, 2370-2378 (1964)

21) Shigematsu, H., Yamano, S. and Yoshimura, $H$. : NAOH-Dependent $\mathrm{O}$-deethylation of $p$ nitropheretole with rabbit liver microsomes. Arch. Biochem. Eiopliys. 137, 178-186 (1976)

22) Shigematsu, $H$. and Yoshida, K.: Possible role of cytochrome P-448 in the O-deethylation of p-nitrophenetole by rat liver microsomes. Chem. Pharm. Bull. (Tokyo) 27, 3002-3008
(1979)

23) Ullrich, V., Frommer, U. and Weber, P.: Differences in the $O$-dealkylation of 7 -ethoxycoumarin after protreatment with phenobarbital and 3-methylcholanthrene. Hoppe Seylers $Z$. Pitysiol. Chem. 354, 514-520 (1973)

24) Jacobson, M., Levin, W., Popper, P.J., Wood, A.W. and Conney, A.H.: Comparison of the Odealkylation of 7-ethoxycoumarin and the hydroxylation of benzo(a)pyrene in human placenta. Clin. Pharmacol. Ther. 16, 701-710 (1974)

25) Greenlee, W.F. and Poland, A.: An improved assay of 7-ethoxycoumarin O-deethylase activity: Induction of hepatic onzyme activity in C57BL/6J and DBA/2J mice by phenobarbital, 3-methylcholanthrene and 2.3.7,8-tetrachlorodibenzo-p-dioxin. J. Pharmacol. Exp. Ther. 205, 596-605 (1978)

26) Schenkman, J.B., Remmer, H. and Estabrook, R.W.: Spectral studies of drug interaction with hepatic microsomal cytochrome. Mol. Pharmacol. 3, 113-123 (1967)

27) Goujon, F.M., Nebert, D.W. and Gielen, J.E.: Genetic expression of aryl hydrocarbon hydroxylaso induction. IV. Interaction of various compounds with different forms of cytochrome P-450 and the effect on benzo(a)pyrene metabolism in vitro. Mol. Pharmacol. 8, 667680 (1972)

28) Kato, R.: Characteristics and differences in the hepatic mixed function oxidases of different species. Pharmacol. Ther. 6, 41-98 (1979)

29) Kamataki, T., Ando, M., Ishii, K. and Kato, R.: inhibition by SKF 525-A of 7-ethoxycoumarin O-deethylation in microsomal and the reconstituted monooxygenase systems from PCBtreated rat livers. Japan. J. Pharmacol. 20, $841-851$ (1980)

30) Levin, W., Ryan, D., Huang, W.T., Kawalek, J.r Thomas, P.E., West, S.B. and Lu, A.Y.H.: Characterization of multiple forms of highly purified cytochrome P-450 from the liver microsomes of rats, mice and rabbits. In Microsomes and Drug Oxidations, Edited by Ulirich. V. Roots, 1., Hildebrandt, A., Estabrook. R.W. and Conney, A.H., p. 185-191. Pergamon Press, Oxford (1977)

31) Nebert, D.W.: Genetic aspocts of onzymo induction by drugs and chemical carcinogens. In The Induction of Drug Motablism, Edited by Fstabrook. R.W. and Lindenlaub. E., p. 419452. F.K. Schattauer Verlag, Stuttgart (1979) 